\title{
Childhood Body-Mass Index and the Risk of Coronary Heart Disease in Adulthood
}

\author{
Jennifer L. Baker, Ph.D., Lina W. Olsen, Ph.D., and Thorkild I.A. Sørensen, M.D., \\ Dr.Med.Sci. \\ Institute of Preventive Medicine, Center for Health and Society, Copenhagen.
}

\begin{abstract}
BACKGROUND-The worldwide epidemic of childhood obesity is progressing at an alarming rate. Risk factors for coronary heart disease (CHD) are already identifiable in overweight children. The severity of the long-term effects of excess childhood weight on CHD, however, remains unknown.

METHODS-We investigated the association between body-mass index (BMI) in childhood (7 through 13 years of age) and CHD in adulthood ( 25 years of age or older), with and without adjustment for birth weight. The subjects were a cohort of 276,835 Danish schoolchildren for whom measurements of height and weight were available. CHD events were ascertained by linkage to national registers. Cox regression analyses were performed.

RESULTS-In 5,063,622 person-years of follow-up, 10,235 men and 4318 women for whom childhood BMI data were available received a diagnosis of CHD or died of CHD as adults. The risk of any CHD event, a nonfatal event, and a fatal event among adults was positively associated with BMI at 7 to 13 years of age for boys and 10 to 13 years of age for girls. The associations were linear for each age, and the risk increased across the entire BMI distribution. Furthermore, the risk increased as the age of the child increased. Adjustment for birth weight strengthened the results.
\end{abstract}

CONCLUSIONS-Higher BMI during childhood is associated with an increased risk of CHD in adulthood. The associations are stronger in boys than in girls and increase with the age of the child in both sexes. Our findings suggest that as children are becoming heavier worldwide, greater numbers of them are at risk of having CHD in adulthood.

WORLDWIDE, CHILDREN ARE BECOMing overweight at progressively younger ages. ${ }^{1}$ In the United States, an estimated 19\% of children 6 to 11 years of age are classified as overweight, with a body-mass index (BMI, the weight in kilograms divided by the square of the height in meters) greater than the 95th percentile for their age and sex according to the Centers for Disease Control and Prevention (CDC) growth charts. ${ }^{2}$ Thus, many children are at risk for weight-related orthopedic problems, social stigmatization, and endocrine abnormalities. 3 The epidemic of childhood obesity is of great concern because, in addition to these concurrent effects of obesity, it is likely that excess weight in childhood will adversely affect health in adulthood.

Risk factors for coronary heart disease (CHD), such as hypertension, dyslipidemia, impaired glucose tolerance, and vascular abnormalities, are already present in overweight children. ${ }^{4-8}$

Copyright () 2007 Massachusetts Medical Society.

Address reprint requests to Dr. Baker at the Institute of Preventive Medicine, Center for Health and Society, Øster Søgade 18, 1st Fl., Copenhagen DK-1357, Denmark, or at jba@ipm.regionh.dk.. 
Excess childhood weight may increase the likelihood of heart disease in adulthood as a result of the early establishment of these risk factors. Given the increasing numbers of overweight children, it is critical to understand how severe the consequences of this excess weight may be on the risk of CHD in adulthood. We therefore investigated whether excess weight in childhood was associated with CHD in adulthood among a very large cohort of persons born in Denmark in 1930 or later.

\section{METHODS STUDY POPULATION}

We studied a cohort of children born from 1930 through 1976 who underwent mandatory annual health examinations at public or private schools in Copenhagen. During the examination, school doctors or nurses measured the children, who were either naked or wearing light clothing. Each child was assigned a health card on which the child's name, date of birth, birth weight as reported by the parents, and yearly height and weight measurements were recorded. This information has been entered into the computerized Copenhagen School Health Records Register. ${ }^{9-11}$

We calculated each child's BMI and, using data from health examinations performed between 1955 and 1960, created internal age- and sex-specific BMI references. Data from these years were used because the prevalence of overweight was low and stable during this period. BMI z scores were calculated by subtracting the BMI for each child from the mean BMI in this fixed reference population and dividing the result by the standard deviation in this reference population. The $\mathrm{z}$ scores were interpolated to exact ages if two measurements were available or extrapolated to exact ages if only one measurement was available. Positive values indicate BMI values above the average in the reference population, and negative values indicate BMI values below the average. Birth weight was recorded on the health cards beginning with the 1943 school year. The children were divided into intervals according to the year of birth (1930 to 1935,1936 to 1939,1940 to 1945,1946 to 1952 , and 1953 to 1976) to account for possible birth-cohort effects.

On April 2, 1968, the National Civil Register of vital statistics was established. ${ }^{12}$ All Danish residents alive on that day or born thereafter were assigned a unique identification number, referred to as their CPR number. Children who were in school at this time or later had the numbers recorded on their health cards. With the use of the CPR number (if available) or information on the name and date of birth, 289,044 computerized records (more than $88 \%$ of the total) were successfully linked to the National Civil Register. The main reasons for nonlinkage were emigration, death, and changes in women's surnames before 1968 .

Information about CHD events was obtained by linking the CPR number to the National Cause of Death Register13 (computerized records were available from 1970) and the National Hospital Discharge Register (established in 1977). ${ }^{14}$ Discharge diagnoses and causes of death were classified according to the International Classification of Diseases, Eighth Revision (ICD-8), before 1994 and the Tenth Revision (ICD-10) thereafter. CHD was defined as ICD-8 codes 410.0 to 414.9 and ICD-10 codes I20.0 to I25.9. The coverage of each register is very high, with virtually every event recorded. ${ }^{13}$, 14 In the Hospital Discharge Register, myocardial infarctions are recorded with a high degree of validity, 15 but in the Cause of Death Register, cardiovascular disease diagnoses are less accurate.13

CHD events were classified as nonfatal or fatal. In analyses of nonfatal outcomes of CHD, only the first nonfatal event was defined as the outcome. In analyses of fatal outcomes, the outcome was defined as recorded in the Cause of Death Register or as death within 28 days after a diagnosis of CHD in the Hospital Discharge Register. 
Follow-up of subjects began at 25 years of age or in 1977 (when the Hospital Discharge Register was established), whichever came later. We chose 25 as the earliest entry age to restrict our analyses to adult outcomes, since CHD events at younger ages often reflect congenital defects and arrhythmia disorders. ${ }^{16}$ Therefore, 280,678 subjects were eligible for our analyses. Follow-up of subjects ended on the date when a CHD event occurred (any event, a fatal event, or a nonfatal event); the date of death, emigration, or loss to follow-up; or December 31, 2001, the date of the last available update from the Cause of Death Register.

\section{STATISTICAL ANALYSIS}

Cox proportional-hazards regression was used to examine the association between BMI $\mathrm{z}$ score at each age from 7 to 13 years and the risk of any CHD event, a nonfatal event, or a fatal event. Analyses were performed with subjects stratified according to birth cohort, separately for each sex, and with and without adjustment for birth weight. The underlying time scale was age. ${ }^{17}$ Potential interactions between birth cohort and BMI z score were investigated in stratified models. Potential interactions between the effects of birth weight and BMI $\mathrm{z}$ score on the risk of CHD were also investigated. The linearity of associations was assessed by testing against a restricted cubic spline with five knots. ${ }^{18}$ To translate the results of the Cox analysis to a prediction of CHD events, we calculated the probability of an event's occurring in an adult between the ages of 25 and 60 years. The predictions were based on an average-size child with a BMI z score of 0 and a larger-than-average child with a BMI z score of 2; the probabilities were calculated separately for boys and girls at 7 and 13 years of age.

\section{RESULTS}

Height and weight measurements were available for 276,835 of the 280,678 eligible subjects $(98.6 \%)$. As expected for children, the BMI values (and standard deviations) increased with age (Table 1). To put the $\mathrm{z}$ scores in perspective, we calculated the amount of weight equivalent to a 1-unit increase in BMI z score at each age (Table 1). During the 46-year period of this study, 10,235 CHD events occurred among men and 4318 among women. There were 5,063,622 person-years of follow-up.

We examined the effect of childhood BMI on the risk of any CHD event, the outcome most relevant for public health. Among boys, there was no interaction between BMI and birth cohort in their effects on the risk of CHD (not shown). The risk of an event in adulthood increased significantly for each 1-unit increase in BMI z score at each age from 7 to 13 years (Fig. 1A). The shape of the association was mainly linear at every age, since the results of tests against the cubic spline were nonsignificant (all $\mathrm{P}$ values $>0.10$ ). These findings show that the risk of CHD in adulthood was highest for boys with the highest BMI values and lowest for boys with the lowest BMI values. Furthermore, the risk of an adult event increased as the child's age increased; for 13-year-old boys, the risk for each 1-unit increase in BMI z score was nearly double that for 7-year-olds.

Similar results were found for girls (Fig. 1B). The only notable difference between girls and boys was that the estimates of the association between BMI and the risk of an event in adulthood were systematically lower in girls. At the ages of 7 and 8 years, the associations were positive and consistent with the overall trend but not statistically significant.

There were 8392 nonfatal events among men and 3637 nonfatal events among women. The overall pattern was similar to that for any CHD event (Table 2). The risk associated with childhood BMI increased with the age of the child, and the association between childhood BMI and adult nonfatal events was linear within each age for boys and girls (not shown). 
There were 3113 fatal events among men and 991 fatal events among women. Again, the risk associated with childhood BMI increased with the age of the child (Table 2), and within each age the association between childhood BMI and adult fatal events was linear for boys and girls. The estimates of the association between BMI and fatal events were greater than those between BMI and nonfatal events alone or between BMI and any CHD event.

Because birth weight has independent and opposing associations with BMI and CHD,10,19 we examined whether adjusting for birth weight would change the observed associations. Among boys, birth weight was associated with the risk of adult CHD in a nonlinear manner (not shown). There were no interactions between the effects of birth weight and BMI on the risk of CHD (any event, a nonfatal event, or a fatal event) (all P values >0.10). Among boys, the associations between BMI at the ages of 7 to 13 years and the risk of CHD (any event, a nonfatal event, or a fatal event) remained significant and were greater in models adjusted for birth weight than in unadjusted models (Table 3, showing the results for any CHD event). Similar results were observed for girls (Table 3).

The probability of having a CHD event between 25 and 60 years of age was calculated for boys and girls of average and higher-than-average BMI. Overall, the probability was not high for either group of children (Table 4). However, in comparison with an average-size 13-year-old boy, a boy of the same age and height weighing $11.2 \mathrm{~kg}$ more had a $33 \%$ higher risk of having a CHD event in adulthood. Similar results were observed for girls.

\section{DISCUSSION}

In this large, population-based cohort study of 276,835 children, we found that higher childhood BMI values elevated the risk of having a CHD event in adulthood. Each 1-unit increase in BMI z score, at every age from 7 to 13 years in boys and from 10 to 13 years in girls, significantly increased the risk of an event. The associations became stronger with increasing age during this period of childhood. As children are becoming heavier worldwide, our findings suggest that more children are at risk of having a CHD event in adulthood.

The large size of our study gave us the statistical power to investigate the effects of childhood BMI separately in relation to sex and age. Among boys, we identified significant associations at each age from 7 to 13 years for any event, nonfatal events, and fatal events. A similar pattern was identified among girls. In studies from Finland, childhood BMI at specific ages was not significantly associated with adult CHD in $4630 \mathrm{men}^{20}$ and 3447 women, ${ }^{21}$ but this result was probably due to inadequate power. We found that the risk of future $\mathrm{CHD}$ associated with childhood BMI increased with the child's age; at 7 years, the risks were small, but by 13 years they had increased considerably in boys and girls. A similar pattern of increase was found in the study of Finnish men. ${ }^{20}$ As children become older, the BMI distribution widens, and the increase in weight required for a 1-unit increase in BMI z score at 13 years of age is more than double that at 7 years. We speculate that, aside from the fact that body size in late childhood is more proximal in time to adult body size, increases in BMI z scores at these later ages could reflect a greater accumulation of fat, in particular intraabdominal fat, which increases the risk of CHD. ${ }^{22}$

Comparisons with studies other than the Finnish ones ${ }^{20,21}$ are challenging, because associations of childhood BMI with CHD according to age and with the same definitions of CHD have rarely been investigated. These methodologic differences probably reflect limitations of the available data sources. Two early studies, one in the United States ${ }^{23}$ and the other in Sweden, ${ }^{24,25}$ found indications that heavier children were at greater risk for cardiovascular disease. A British study of 2399 children aged 2 to 14 years reported an 
association between childhood BMI and death from ischemic heart disease. ${ }^{26}$ Unlike our study, however, this study did not find significant associations when the data for boys and girls were analyzed separately. ${ }^{26}$

An investigation of 11,106 Scottish children with a mean age of 4.9 years did not detect an effect of childhood BMI on CHD. ${ }^{27}$ In our study, the associations were moderate for children at 7 years of age and then increased with age. Thus, it is possible that these associations do not exist for younger children or that the Scottish study lacked sufficient power to detect an effect. A recent meta-analysis did not detect an effect of BMI on future ischemic heart disease, but considerable uncertainty remains because of the wide age range of the subjects ( 2 to 22 years). ${ }^{28}$ In accordance with our findings, the results of most of these studies indicate that higher childhood BMI is associated with a greater risk of some aspect of cardiovascular disease in adulthood.

Currently, children are typically classified as being at risk only if their BMI values are above cutoff points such as the 85th or 95th percentile on growth charts. Our results do not support this approach. The linearity of the associations we identified between childhood BMI and adult CHD implies that even a surprisingly small amount of weight gain (illustrated in Table 4) will increase the risk of CHD.

We investigated whether birth weight would modify the associations between childhood BMI and CHD, since it has independent associations with these factors. ${ }^{10,29}$ No interactions were identified, even in our large data set with sufficient statistical power to detect them if they had been present. We found that, after adjustment for birth weight, the effect of an increase in BMI z score on the risk of CHD in adulthood remained and that this effect was greater than that in models containing only BMI. These results show that childhood BMI, even after the effects of birth weight have been taken into account, is associated with CHD in adulthood. From a public health perspective, focusing on the effect of BMI alone is of greater importance because it is modifiable, whereas birth weight is not.

Our study is based on a unique and very large population-based cohort. The register includes virtually every schoolchild in Copenhagen from 1930 to 1976. Health examinations were performed at all public and private schools, thus eliminating selection bias due to socioeconomic status. Unlike other studies in this area of research, complete follow-up was available for every eligible subject in the study as a result of the efficiency of the National Civil Register. Data on the ethnic background of the schoolchildren are not available, but since less than $3.1 \%$ of the population of Copenhagen was of non-European origin in $1980^{30}$ (the earliest year for which information on ethnic background is available), it can be assumed that nearly all our subjects were white. The population-based nature of our cohort, the complete follow-up, and the ethnic background of the cohort suggest that the results of our study are generalizable to other populations of white descent.

Investigations of the risk factors for CHD have shown that hypertension, dyslipidemia, impaired glucose tolerance, and vascular abnormalities are already present in overweight children. ${ }^{4-8}$ Higher body weight in childhood is associated with the presence of these risk factors in children, ${ }^{4,31}$ and this association suggests a plausible mechanism linking higher childhood BMI with an increased risk of adult CHD. It is also possible that childhood BMI is associated with CHD as a result of its relation with adult BMI. Correlations between childhood and adult BMI exist; however, they vary in magnitude, and not every heavy child becomes a heavy adult, nor was every heavy adult a heavy child. ${ }^{11,32,33} \mathrm{We}$ do not have information on adult body size for our subjects. Nonetheless, the ability to identify boys and girls who are at risk because of their childhood BMI, whatever their BMI may be when they become adults, is important for the prevention of future CHD. An analysis of the relation 
between adolescent BMI and adult CHD found that the effects were independent of adult BMI, although this study was conducted on subjects older than those in our study. ${ }^{34}$

The subjects of our study were born from the 1930s onward and therefore include children born before and during the emergence of the obesity epidemic. ${ }^{35-37} \mathrm{We}$ found that the association between childhood BMI and adult CHD was the same irrespective of which birth cohort the children came from. Several studies have demonstrated that socioeconomic status in childhood is inversely associated with the risk of CHD, but these associations often diminish when adult socioeconomic status is taken into account.38,39 Information about socioeconomic status was not available for our cohort. In a study of childhood BMI and adult heart disease, the associations remained virtually unchanged when adjustments were made for childhood and adult socioeconomic status.26 Of course, it cannot be ruled out that socioeconomic status, through its associations with different behavioral and psychosocial risk factors, has a direct effect on CHD independent of childhood body weight. However, because childhood obesity is already associated with distinct biologic risk factors for CHD, ${ }^{4}$ it is likely that the associations we observed are based on biologic effects of the children's BMI. Moreover, the population-based nature of our sample (which included all socioeconomic-status groups) and the dramatic societal, environmental, and medical changes that occurred throughout the time period under study make it unlikely that differences in socioeconomic status explain the effects of childhood BMI that we observed. We indirectly adjusted for these factors by stratifying the analyses according to birth cohort, and the association was surprisingly stable across birth cohorts, a result suggesting that the mechanism of the association is probably biologic in nature.

Contemporary children are heavier than their counterparts from the past. In the United States, there is no sign that the increases in childhood overweight and obesity are slowing down, ${ }^{2}$ and the situation is similar in Denmark. ${ }^{40}$ The linear association we identified between childhood BMI and adult CHD suggests that more children than ever before are facing increased risks of CHD in adulthood. To put these results in perspective, we calculated the children's probability of having a future CHD event. The example of a 13year-old boy who weighs $11.2 \mathrm{~kg}$ more than average - which results in a $33 \%$ increase in the probability of his having a CHD event before the age of 60 - illustrates the deleterious effect of childhood obesity on future health. The BMI values of average and larger-thanaverage boys in this prediction correspond to the 41st and 88th percentiles, respectively, of the BMI-for-age references of the CDC; thus, these predictions are based on boys who fit within the range of body size of contemporary children. ${ }^{41}$ Similar predictions were obtained for girls. Nonetheless, since the magnitude of the risk was moderate for 7-year-olds and increased dramatically by the age of 13 , these results suggest the possibility of intervention during this period of childhood to reduce the risk of future CHD.

In this study, we determined that higher BMI values in childhood are associated with a greater risk of $\mathrm{CHD}$ in adulthood. Furthermore, these risks increase with increasing age of the children. Cutoff points at which the risk dramatically increased were not identified; the risk increased across the spectrum of BMI values. Because more children are becoming heavier at progressively younger ages, our results suggest that a focus should be placed on helping children to attain and maintain appropriate weight to prevent future adverse health consequences.

\section{Acknowledgments}

Supported by grants from the National Institute of Diabetes and Digestive and Kidney Diseases (F32DK070491) and the Danish Heart Foundation (04-10-B191-A285-22201 to Dr. Olsen) and by the Danish National Science Foundation. 
No potential conflict of interest relevant to this article was reported.

We thank Dr. Bente Hansen and Dr. Seija Pearson and the other school health doctors and nurses from the Copenhagen Municipality School Health Services for their continued work with the children.

\section{References}

1. Rössner S. Obesity: the disease of the twenty-first century. Int J Obes Relat Metab Disord. 2002; 26(Suppl 4):S2-S4. [PubMed: 12457290]

2. Ogden CL, Carroll MD, Curtin LR, McDowell MA, Tabak CJ, Flegal KM. Prevalence of overweight and obesity in the United States, 1999-2004. JAMA. 2006; 295:1549-55. [PubMed: 16595758]

3. Must A, Strauss RS. Risks and consequences of childhood and adolescent obesity. Int J Obes Relat Metab Disord. 1999; 23(Suppl 2):S2-S11. [PubMed: 10340798]

4. Weiss R, Dziura J, Burgert TS, et al. Obesity and the metabolic syndrome in children and adolescents. N Engl J Med. 2004; 350:2362-74. [PubMed: 15175438]

5. Viner RM, Segal TY, Lichtarowicz-Krynska E, Hindmarsh P. Prevalence of the insulin resistance syndrome in obesity. Arch Dis Child. 2005; 90:10-4. [PubMed: 15613503]

6. Sinha R, Fisch G, Teague B, et al. Prevalence of impaired glucose tolerance among children and adolescents with marked obesity. N Engl J Med. 2002; 346:802-10. [PubMed: 11893791] [Erratum, N Engl J Med 2002;346: 1756.]

7. Tounian P, Aggoun Y, Dubern B, et al. Presence of increased stiffness of the common carotid artery and endothelial dys-function in severely obese children: a prospective study. Lancet. 2001; 358:1400-4. [PubMed: 11705484]

8. Berenson GS, Srinivasan SR, Bao W, Newman WP III, Tracy RE, Wattigney WA. Association between multiple cardiovascular risk factors and atherosclerosis in children and young adults: the Bogalusa Heart Study. N Engl J Med. 1998; 338:1650-6. [PubMed: 9614255]

9. Ahlgren M, Melbye M, Wohlfahrt J, Sørensen TIA. Growth patterns and the risk of breast cancer in women. N Engl J Med. 2004; 351:1619-26. [PubMed: 15483280]

10. Rugholm S, Baker JL, Olsen LW, Schack-Nielsen L, Bua J, Sørensen TIA. Stability of the association between birth weight and childhood overweight during the development of the obesity epidemic. Obes Res. 2005; 13:2187-94. [PubMed: 16421354]

11. Sørensen TIA, Sonne-Holm S. Risk in childhood of development of severe adult obesity: retrospective, population-based case-cohort study. Am J Epidemiol. 1988; 127:104-13. [PubMed: 3337071]

12. Pedersen CB, Gøtzsche H, Møller JO, Mortensen PB. The Danish Civil Registration System: a cohort of eight million persons. Dan Med Bull. 2006; 53:441-9. [PubMed: 17150149]

13. Juel K, Helweg-Larsen K. The Danish registers of causes of death. Dan Med Bull. 1999; 46:354-7. [PubMed: 10514943]

14. Andersen TF, Madsen M, Jørgensen J, Mellemkjær L, Olsen JH. The Danish National Hospital Register: a valuable source of data for modern health sciences. Dan Med Bull. 1999; 46:263-8. [PubMed: 10421985]

15. Madsen M, Davidsen M, Rasmussen S, Abildstrøm SZ, Osler M. The validity of the diagnosis of acute myocardial infarction in routine statistics: a comparison of mortality and hospital discharge data with the Danish MONICA registry. J Clin Epidemiol. 2003; 56:124-30. [PubMed: 12654406]

16. Puranik R, Chow CK, Duflou JA, Kil-born MJ, McGuire MA. Sudden death in the young. Heart Rhythm. 2005; 2:1277-82. [PubMed: 16360077]

17. Andersen, PK.; Borgan, $\varnothing$.; Gill, RD.; Keiding, N. Statistical models based on counting processes. Springer-Verlag; New York: 1993.

18. Greenland S. Dose-response and trend analysis in epidemiology: alternatives to categorical analysis. Epidemiology. 1995; 6:356-65. [PubMed: 7548341]

19. Barker DJ, Winter PD, Osmond C, Margetts B, Simmonds SJ. Weight in infancy and death from ischaemic heart disease. Lancet. 1989; 2:577-80. [PubMed: 2570282] 
20. Eriksson JG, Forsén T, Tuomilehto J, Osmond C, Barker DJ. Early growth and coronary heart disease in later life: longitudinal study. BMJ. 2001; 322:949-53. [PubMed: 11312225]

21. Forsén T, Eriksson JG, Tuomilehto J, Osmond C, Barker DJ. Growth in utero and during childhood among women who develop coronary heart disease: longitudinal study. BMJ. 1999; 319:1403-7. [PubMed: 10574856]

22. Zimmet P, Alberti G, Kaufman F, et al. The metabolic syndrome in children and adolescents. Lancet. 2007; 369:2059-61. [PubMed: 17586288]

23. Abraham S, Collins G, Nordsieck M. Relationship of childhood weight status to morbidity in adults. HSMHA Health Rep. 1971; 86:273-84. [PubMed: 5547793]

24. Mossberg HO. 40-Year follow-up of overweight children. Lancet. 1989; 2:491-3. [PubMed: 2570196]

25. DiPietro L, Mossberg HO, Stunkard AJ. A 40-year history of overweight children in Stockholm: life-time overweight, morbidity, and mortality. Int J Obes Relat Metab Disord. 1994; 18:585-90. [PubMed: 7812410]

26. Gunnell DJ, Frankel SJ, Nanchahal K, Peters TJ, Davey Smith G. Childhood obesity and adult cardiovascular mortality: a 57-y follow-up study based on the Boyd Orr cohort. Am J Clin Nutr. 1998; 67:1111-8. [PubMed: 9625081]

27. Lawlor DA, Leon DA. Association of body mass index and obesity measured in early childhood with risk of coronary heart disease and stroke in middle age: findings from the Aberdeen children of the 1950s prospective cohort study. Circulation. 2005; 111:1891-6. [PubMed: 15837941]

28. Lawlor DA, Martin RM, Gunnell D, et al. Association of body mass index measured in childhood, adolescence, and young adulthood with risk of ischemic heart disease and stroke: findings from 3 historical cohort studies. Am J Clin Nutr. 2006; 83:767-73. [PubMed: 16600926]

29. Barker, DJP. Mothers, babies, and disease in later life. BMJ Publishing Group; London: 1994.

30. Statbank Denmark. Danmarks statistiks. 2006 [November 9, 2007]. (at http://www.dst.dk.)

31. Meyer AA, Kundt G, Steiner M, Schuff-Werner P, Kienast W. Impaired flow-mediated vasodilation, carotid artery intima-media thickening, and elevated endothelial plasma markers in obese children: the impact of cardiovascular risk factors. Pediatrics. 2006; 117:1560-7. [PubMed: 16651309]

32. Power C, Lake JK, Cole TJ. Body mass index and height from childhood to adulthood in the 1958 British born cohort. Am J Clin Nutr. 1997; 66:1094-101. [PubMed: 9356525]

33. Reilly JJ, Methven E, McDowell ZC, et al. Health consequences of obesity. Arch Dis Child. 2003; 88:748-52. [PubMed: 12937090]

34. Must A, Jacques PF, Dallal GE, Bajema CJ, Dietz WH. Long-term morbidity and mortality of overweight adolescents: a follow-up of the Harvard Growth Study of 1922 to 1935. N Engl J Med. 1992; 327:1350-5. [PubMed: 1406836]

35. Olsen LW, Baker JL, Holst C, Sørensen TIA. Birth cohort effect on the obesity epidemic in Denmark. Epidemiology. 2006; 17:292-5. [PubMed: 16570023]

36. Thomsen BL, Ekstrøm CT, Sørensen TIA. Development of the obesity epidemic in Denmark: cohort, time and age effects among boys born 1930-1975. Int J Obes Relat Metab Disord. 1999; 23:693-701. [PubMed: 10454102]

37. Bua J, Olsen LW, Sørensen TIA. Secular trends in childhood obesity in Denmark during 50 years in relation to economic growth. Obesity (Silver Spring). 2007; 15:977-85. [PubMed: 17426333]

38. Galobardes B, Lynch JW, Davey Smith G. Childhood socioeconomic circumstances and causespecific mortality in adulthood: systematic review and interpretation. Epidemiol Rev. 2004; 26:721. [PubMed: 15234944]

39. Strand BH, Kunst A. Childhood socioeconomic position and cause-specific mortality in early adulthood. Am J Epidemiol. 2007; 165:85-93. [PubMed: 17041134]

40. Pearson S, Olsen LW, Hansen B, Sørensen TIA. Increase in overweight and obesity amongst Copenhagen schoolchildren, 1947-2003. Ugeskr Laeger. 2005; 167:158-62. (In Danish.). [PubMed: 15697126]

41. Kuczmarski, RJ.; Odgen, CL.; Grummer-Strawn, LM., et al. CDC growth charts: United States. Advance data from vital and health statistics. No. 314. National Center for Health Statistics; Hyattsville, MD: 2000. 


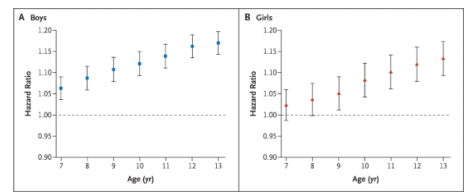

Figure 1. Body-Mass Index (BMI) in Childhood and the Risk of Coronary Heart Disease (CHD) in Adulthood

The graphs depict the association between childhood BMI and the risk of having a CHD event (nonfatal or fatal) in adulthood. Hazard ratios and 95\% confidence intervals are given for a 1-unit increase in BMI z score at each age from 7 to 13 years. The data are from 139,857 boys (Panel A) and 136,978 girls (Panel B) in the Copenhagen School Health Records Cohort. The associations were linear within each age, since trend tests resulted in the rejection of the alternative of nonlinearity modeled as a restricted cubic spline with five knots (all $\mathrm{P}$ values $>0.15$ ). 
Table 1

Mean BMI Values for 276,835 Children 7 to 13 Years of Age.*

\begin{tabular}{|c|c|c|c|c|}
\hline \multirow[t]{3}{*}{ Age } & \multicolumn{2}{|r|}{ Boys $(N=139,857)$} & \multicolumn{2}{|r|}{ Girls $(\mathrm{N}=136,978)$} \\
\hline & BMI & $\begin{array}{l}\text { Weight Equivalent to a 1-Unit Increase in BMI z } \\
\qquad \text { Score }^{\dagger}\end{array}$ & BMI & $\begin{array}{l}\text { Weight Equivalent to a 1-Unit Increase in BMI z } \\
\text { Score }{ }^{\dagger}\end{array}$ \\
\hline & mean $\pm S D$ & kg & mean $\pm S D$ & kg \\
\hline $7 \mathrm{yr}$ & $15.5 \pm 1.2$ & 1.96 & $15.4 \pm 1.4$ & 2.17 \\
\hline $8 \mathrm{yr}$ & $15.8 \pm 1.3$ & 2.44 & $15.8 \pm 1.5$ & 2.66 \\
\hline $9 \mathrm{yr}$ & $16.2 \pm 1.5$ & 2.96 & $16.2 \pm 1.7$ & 3.25 \\
\hline $10 \mathrm{yr}$ & $16.6 \pm 1.6$ & 3.58 & $16.6 \pm 1.9$ & 3.91 \\
\hline $11 \mathrm{yr}$ & $17.0 \pm 1.8$ & 4.22 & $17.1 \pm 2.0$ & 4.67 \\
\hline $12 \mathrm{yr}$ & $17.5 \pm 2.0$ & 4.90 & $17.8 \pm 2.2$ & 5.58 \\
\hline $13 \mathrm{yr}$ & $18.1 \pm 2.1$ & 5.60 & $18.6 \pm 2.4$ & 6.30 \\
\hline
\end{tabular}

BMI denotes body-mass index, which is the weight in kilograms divided by the square of the height in meters. Values are from the Copenhagen School Health Records Register.

${ }^{\dagger}$ Calculations are based on children of average height at each age. 
Table 2

Adjusted Hazard Ratio for the Risk of a Fatal or a Nonfatal CHD Event in Adulthood in Relation to a 1-Unit Increase in BMI z Score in a Cohort of 276,835 Children. ${ }^{*}$

\begin{tabular}{|lccccc|}
\hline Age & \multicolumn{2}{c}{ Nonfatal Event } & \multicolumn{2}{c|}{ Fatal Event } \\
& Boys & Girls & Boys & Girls \\
& & relative risk (95\% confidence interval) ${ }^{\dagger}$ & \\
$7 \mathrm{yr}$ & $1.05(1.03-1.08)$ & $1.02(0.98-1.06)$ & $1.10(1.06-1.15)$ & $1.07(0.99-1.15)$ \\
$8 \mathrm{yr}$ & $1.08(1.05-1.11)$ & $1.02(0.98-1.06)$ & $1.14(1.09-1.19)$ & $1.08(1.01-1.17)$ \\
$9 \mathrm{yr}$ & $1.10(1.07-1.12)$ & $1.03(0.99-1.07)$ & $1.16(1.11-1.21)$ & $1.10(1.02-1.19)$ \\
$10 \mathrm{yr}$ & $1.11(1.08-1.14)$ & $1.06(1.02-1.10)$ & $1.18(1.13-1.23)$ & $1.12(1.04-1.20)$ \\
$11 \mathrm{yr}$ & $1.13(1.10-1.16)$ & $1.07(1.03-1.12)$ & $1.22(1.17-1.27)$ & $1.18(1.10-1.27)$ \\
$12 \mathrm{yr}$ & $1.15(1.13-1.18)$ & $1.10(1.06-1.14)$ & $1.23(1.18-1.28)$ & $1.20(1.11-1.29)$ \\
$13 \mathrm{yr}$ & $1.17(1.14-1.20)$ & $1.11(1.07-1.15)$ & $1.24(1.19-1.29)$ & $1.23(1.15-1.32)$ \\
\hline
\end{tabular}

* Analyses were stratified according to birth cohort.

${ }^{\dagger}$ Trend tests led to the rejection of the alternative of nonlinearity modeled as a restricted cubic spline with five knots (all $\mathrm{P}$ values $>0.10$ ). 
Table 3

Adjusted Hazard Ratio for the Risk of Any CHD Event in Adulthood in Relation to a 1-Unit Increase in BMI z Score in Models Unadjusted and Adjusted for Birth Weight in a Cohort of 208,433 Children. ${ }^{*}$

\begin{tabular}{|lcccc|}
\hline Age & \multicolumn{2}{c}{ Boys } & \multicolumn{2}{c|}{ Girls } \\
& $\begin{array}{c}\text { Model Unadjusted for Birth } \\
\text { Weight }\end{array}$ & $\begin{array}{c}\text { Model Adjusted for Birth } \\
\text { Weight } \\
\text { relative risk }\end{array}$ & $\begin{array}{c}\text { Model Unadjusted for Birth } \\
\text { Weight }\end{array}$ & $\begin{array}{c}\text { Model Adjusted for Birth } \\
\text { Weight }\end{array}$ \\
$7 \mathrm{yr}$ & $1.09(1.05-1.12)$ & $1.10(1.07-1.14)$ & $1.04(1.00-1.09)$ & $1.05(1.00-1.10)$ \\
$8 \mathrm{yr}$ & $1.11(1.08-1.15)$ & $1.13(1.10-1.17)$ & $1.05(1.00-1.10)$ & $1.06(1.01-1.11)$ \\
$9 \mathrm{yr}$ & $1.13(1.10-1.17)$ & $1.15(1.12-1.19)$ & $1.06(1.01-1.11)$ & $1.07(1.02-1.12)$ \\
$10 \mathrm{yr}$ & $1.15(1.11-1.18)$ & $1.16(1.13-1.20)$ & $1.09(1.04-1.15)$ & $1.10(1.05-1.15)$ \\
$11 \mathrm{yr}$ & $1.17(1.14-1.20)$ & $1.19(1.15-1.22)$ & $1.11(1.06-1.17)$ & $1.12(1.07-1.17)$ \\
$12 \mathrm{yr}$ & $1.20(1.16-1.23)$ & $1.21(1.18-1.25)$ & $1.13(1.08-1.19)$ & $1.14(1.09-1.19)$ \\
$13 \mathrm{yr}$ & $1.20(1.17-1.24)$ & $1.22(1.19-1.26)$ & $1.15(1.10-1.20)$ & $1.15(1.10-1.21)$ \\
\hline
\end{tabular}

* Analyses were stratified according to birth cohort. Birth weight is modeled as a cubic spline with five knots. Birth weight was recorded from 1943 and was available for 208,433 of the boys and girls.

${ }^{\dagger}$ Trend tests led to the rejection of the alternative of nonlinearity modeled as a restricted cubic spline with five knots (all $\mathrm{P}$ values $>0.15$ ). 


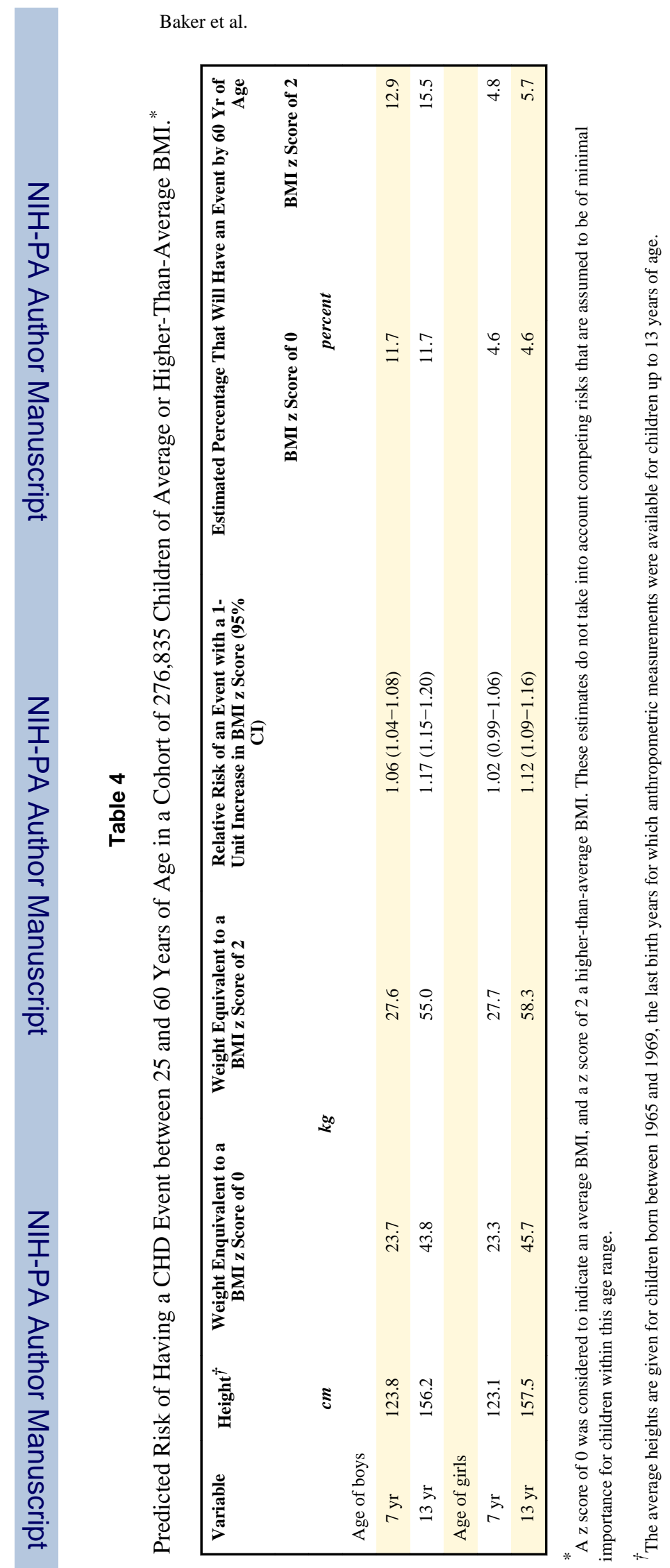

N Engl J Med. Author manuscript; available in PMC 2011 March 23. 